\title{
Captivity for Conservation? Zoos at a Crossroads
}

\author{
Jozef Keulartz
}

Accepted: 22 February 2015/Published online: 13 March 2015

(C) The Author(s) 2015. This article is published with open access at Springerlink.com

\begin{abstract}
This paper illuminates a variety of issues that speak to the question of whether 'captivity for conservation' can be an ethically acceptable goal of the modern zoo. Reflecting on both theoretical disagreements (animal protectionists vs. wildlife conservationists) and practical challenges (the small percentage of endangered species actually exhibited in zoos, disappointing success of reintroduction programs), the paper explains why the 'Noah's Ark' paradigm is being replaced by an alternative 'integrated approach.' It explores the changes in the zoo's core tasks that the new paradigm implies. And it pays special attention to the changes that would have to be made in zoos' collection policies: connection with in situ projects, emphasizing local species and the local biogeographical region, exchange of animals among zoos and between zoos and wildlife, and a shift towards smaller species. Finally the question will be addressed whether the new paradigm will achieve a morally acceptable balance between animal welfare costs and species conservation benefits.
\end{abstract}

Keywords Future zoo $\cdot$ Animal welfare $\cdot$ Species conservation $\cdot$ Metapopulation management

\section{Introduction}

Today, the animal world is under severe attack as a result of two strongly interconnected global processes. On the one hand, global environmental changes

\section{J. Keulartz (ه)}

Emeritus Professor of Environmental Philosophy, Radboud University, Nijmegen, The Netherlands e-mail: J.Keulartz@science.ru.nl

\section{J. Keulartz}

Wageningen University, Wageningen, The Netherlands 
such as climate change, land use and land cover change, deforestation and desertification have a disruptive impact on plant and animal life. Entire populations are being confronted with the alternative to abandon their original habitat or to go extinct. On the other hand, globalization causes massive dislocations of entire populations. As trade, travel, transport and tourism boom, the world is becoming more and more borderless and, by the same token, it is becoming increasingly vulnerable to invasive species. Since globalization took off, more plants and animals have become globetrotters than ever before (Keulartz and Swart 2012).

Because animals are constantly on the move worldwide as a result of these global processes, traditional in situ (place-based) conservation methods seem no longer sufficient to save threatened species (Sandler 2012). The magnitude of anthropogenic environmental stress from bioinvasion, habitat fragmentation, nitrogen deposition, biodiversity loss, and, above all, climate change, makes it unavoidable to replace the hands-off approach that has guided mainstream species conservation until recently by a more proactive and interventionist strategy.

However, this new strategy has led to manifold conflicts between wildlife conservationists and animal protectionists (Minteer and Collins 2013). As Michael Soule has remarked in his presidential address at the third annual meeting of the Society for Conservation Biology in 1989: "Conflicts between animal rights groups and management agencies are increasing in frequency and cost—-the cost being borne by endangered species and ecosystems as well as by the public that pays for expensive rescue operations and time-consuming court battles" (Soule 1990, 235).

In his address, Soulé claimed that among the many environmental challenges of the coming decades, 'the onslaught of alien species' would be the most revolutionary. And he foresaw that attempts by conservationists to control destructive exotics would meet resistance from 'well-meaning animal welfare enthusiasts', who oppose eradication programs that involve techniques such as hunting and trapping or make use of pesticides such as piscicides, chemical substances which are poisonous to fish (Keulartz and Van der Weele 2008). ${ }^{1}$

Another potential area of conflict between wildlife conservationists and animal activists concerns managed relocation (also known as assisted colonization or assisted migration). The human-aided relocation of threatened species may be required when their historical ranges have become inhospitable due to climate change or habitat fragmentation and destruction, and when moving on their own to other regions where environmental conditions are more suitable is impossible. Relocated animals will inevitable experience chronic stress at all stages of the process, from capture and captivity to transport and release to novel areas. Such relocation-induced chronic stress increases the overall vulnerability of the individuals and, as a result, decreases the probability that the population will become self-sustaining (Dickens et al. 2010).

\footnotetext{
${ }^{1}$ A famous example of the clash over programs to eradicate invasive species is the controversy about the feral pigs in Hawaii, between the Nature Conservancy and People for the Ethical Treatment of Animals (PETA). While conservation biologists have argued that the pigs should be killed and removed because they threaten Hawaii's biodiversity, animal activists argued that it is wrong to harm and kill the pigs because they are sentient animals (Woods and Moriarty 2001).
} 
Here, I will focus on yet another major battlefield between wildlife conservationists and animal activists: ex situ conservation through zoos and aquaria. As a response to the ongoing decline in effectiveness of in situ conservation and the accompanying loss of biodiversity, zoos began to turn their attention to the conservation of endangered species and wildlife in the 1970s and 1980s. Captivity for Conservation became a crucial slogan for the modern zoo. A major milestone in this development was the Convention on Biodiversity which was signed at the Earth Summit in Rio de Janeiro in 1992. In the wake of the Earth Summit the first World Zoo Conservation Strategy was launched in 1993. Its conclusion explicitly stated that, at a time when species, habitats and ecosystems worldwide are threatened with extinction, modern zoos must commit to the conservation of species and wildlife.

Caring for our planet's biological systems is one of the greatest challenges to humankind. Consequently, conservation is being seen as the central theme of zoos, and zoos should thus further evolve into conservation centers (WAZA 1993, 3).

In this scheme of things the zoo was envisaged as a kind of Noah's Ark which owed its raison d'être primarily to its contribution to the conservation of species through breeding and reintroduction programs. As the main institution for ex situ conservation of wild animal species, the zoo was now confronted head-on with the potential conflicts between animal protectionists and wildlife conservationists.

In this essay, I will analyze the moral issues at stake in these conflicts over the zoo with an eye to possibilities to bridge the differences between the conflicting parties. I will argue that both sides of the controversy may find common ground in the view that zoos will be morally justifiable only if the costs in terms of animal welfare and freedom are clearly outweighed by the benefits to species preservation. Next, I will argue that the Noah's Ark paradigm does not meet this standard, that it therefore has lost credibility and has gradually given way to a new paradigm: the 'integrated approach' in which the zoo is primarily seen as a conservation park or center. I will then set out the implications of the new approach for the zoo's core tasks and explore the collection policy options that are open to zoos in order to carry out these tasks in the best possible way. Finally, I will address the question whether the new paradigm may achieve a morally acceptable balance between animal welfare costs and species conservation benefits. But in order to understand what is at stake in the battle over the zoo's legitimacy and right to existence I will first take a closer look at the heated philosophical debate between animal ethicists and environmental ethicists.

\section{The Animal Ethics/Environmental Ethics Debate}

The philosophical debate between animal ethicists and environmental ethicist erupted around 1980 (Hargrove 1992). Before that time it was expected that an adequate environmental ethics would develop as a natural extension of animal ethics. Both Peter Singer's animal liberation theory and Tom Regan's animal rights theory denounced traditional morality for its 'human chauvinism' and its 
'speciesism'. The time seemed ripe for a moral rehabilitation of the rest of animate nature, and animal ethicists and environmental ethicists were supposed to join forces in fighting for wildlife preservation. But, as Sagoff (1984) has remarked somewhat sarcastically, this was a 'bad marriage', followed by a 'quick divorce'.

In 1980, Baird Callicott published a highly polemical article to counter the widespread view that the existing animal ethics of Singer en Regan were fully capable of answering all environmental ethical questions. In particular, Callicott opposed their view that only individual animals have intrinsic value and direct moral standing, not collective entities such as species or ecosystems. While Singer believes that we have no duties to species because as such they "are not conscious entities and so do not have interests above and beyond the interests of the individual animals that are members of the species" (Singer 1979, 203), Regan holds that "the rights view does not recognize the moral rights of species to anything, including survival” (Regan 1983, 359).

According to Callicott, animal ethicists demonstrate their 'ecological illiteracy' by pleading for a responsibility to maintain individual animals irrespective of whether these are tame or wild, rare or common, indigenous or exotic. In line with Aldo Leopold's 'land ethic', he advocated a holistic approach in which individual organisms are perceived as parts of the biotic community. Such an approach does not accord equal moral worth to each and every member of the biotic community; "the moral worth of individuals is relative, to be assessed in accordance with the particular relation of each to the collective entity which Leopold called 'land", (Callicott 1980, 327).

Holmes Rolston, one of the founding fathers of environmental ethics, based his holistic view on a neo-Darwinian account of the evolutionary history of life on earth. He writes: "In an evolutionary ecosystem it is not mere individuality that counts; species is also significant because it is a dynamic life form maintained over time by an informed genetic flow. The individual represents (re-presents) a species in each new generation. It is a token of a type, and the type is more important than the token" (Rolston 1988, 143). It follows that "the individual is subordinate to the species, not the other way around" (ibid. 149).

Tom Regan responded to these attacks against the animal ethicists' basic principle with the accusation that environmental ethicists were committing the crime of 'environmental fascism' by subordinating the rights of individuals to the interests of the greater whole. "Environmental fascism and the rights view are like oil and water, they don't mix" (Regan 1983, 362).

Animal ethicists and environmental ethicists usually not only differ with regard to the locus of moral concern-individual organisms or greater wholes-they also tend to use different species concepts (Sandler 2012, 4). Animal ethicists have generally adopted a conventionalist species concept; they see a species merely as a category or class with arbitrarily drawn boundary lines that may serve as a convenient mapping device for theoretical purposes only. ${ }^{2}$ Environmental ethicists,

\footnotetext{
${ }^{2}$ According to Dale Jamieson "the notion of a species is an abstraction; the idea of its welfare is a human construction. While there is something that it is like to be an animal there is nothing that it is like to be a species" (Jamieson 1995, 61).
} 
on the other hand, generally hold a realistic species concept. Rolston, for instance, argues that a species is a real historical entity, a 'dynamic historical lineage' that can persist as a discrete, vital pattern over time (Rolston 1988, 151). ${ }^{3}$

While it is evident that conflicts between individualistic animal-centered and holistic species-centered ethicists and activists will increase as conservation strategies will inevitable become more and more interventionist and hands-on, the gap between these divergent views simply seems too wide to bridge, even in cases where advocates of both sides have common cause (Minteer and Collins 2013, 43). Such seemingly intractable controversies are often not resolvable by recourse to facts and unlikely to be settled by compromise. They require what Donald Schön and Martin Rein, inspired by John Dewey's idea of 'reconstructive thinking', have called 'frame restructuring', i.e. the attempt to integrate conflicting frames.

As a necessary first step towards such an integration, both sides of the controversy regarding the moral acceptability of zoos have to develop a 'double vision', namely "the ability to act from a frame while cultivating awareness of alternative frames" (Schön and Rein 1994, 207). They should learn to 'squint' so to speak in order to see things from both angels simultaneously. Only then will it be possible to find a morally defensible balance between animal welfare concerns on the one hand and species conservation commitments on the other.

\section{Balancing Animal Welfare/Rights Against Species Conservation}

Most animal rights proponents will resist any attempts at such value balancing. They consider infringing an individual's right to freedom for the sake of the preservation of the species as morally wrong. For Regan any type of captivity or manipulation of a sentient animal is morally unacceptable, irrespective of the possibly beneficial consequences for the protection of rare or endangered species. The rights view's answer to the question whether zoos are morally defensible, "not surprisingly, is No, they are not" (Regan 1995, 46).

Utilitarians like Singer, on the other hand, do allow for value balancing and accept reductions in animal welfare when the survival of entire populations or species is at stake. A case in point is Singer's approach to the problem of the South American cane toad that was introduced to Australia as a method of agricultural pest control, but became itself a serious pest for native wildlife. Whereas animal rights groups fiercely opposed the eradication of cane toads because they believe that killing an animal, unless to end suffering, is always bad, Singer argued that "where killing can be done humanely, and is necessary to preserve endangered species, it may be defensible." 4

When Singer was recently asked whether zoos should exist for the sake of species preservation, he answered as follows, "I think if a species is likely to become extinct in the wild and you can capture the animals humanely and recreate the physical and behavioral conditions, then could release them or their progeny in the wild, then that

\footnotetext{
${ }^{3}$ For a recent contribution to the animal ethics/environmental ethics debate, see McShane (2014).

${ }^{4}$ http://www.abc.net.au/environment/articles/2011/01/17/3113142.htm.
} 
function of zoos is defensible." 5 Singer feels, however, that most zoos today fail to live up to their conservation mission. They tend to confine animals for our amusement in ways that are contrary to their interests. Even if these zoos do occasionally preserve an endangered species, "what is the point of preserving animals if they are having miserable lives?" 6

Dale Jamieson, another animal ethicist working in the utilitarian tradition, ${ }^{7}$ is even more skeptical about zoos than Peter Singer. As starting point for his assessment of the moral defensibility of the zoo, Jamieson claims that keeping animals in captivity is wrong, unless a case can be made that the benefits outweigh the moral presumption against depriving animals of liberty. In his classic essay 'Against Zoos' from 1985, Jamieson concludes that the supposed benefits of zoosamusement, education, scientific research and species preservation-are outweighed by the moral presumption against keeping animals. Ten years latter, he repeated his analysis with a strong focus on the modern zoo's most compelling reason for its existence, its contribution to species conservation. And again Jamieson's final judgment proved unfavorable for the zoo; he considered the benefit of preservation "not significant enough to overcome the presumption against depriving an animal of its liberty" (Jamieson 1995, 60).

\section{Noah's Ark in Rough Water}

Jamieson's verdict was, to a considerable extent, shared by an increasing number of critiques within the zoo-community. The vision of the zoo as a Noah's Ark started to shipwreck as the breeding programs ran into some substantial problems. Many of the animals exhibited in zoos do not belong to groups designated for conservation. Because the space for all the zoo animals in the world could easily fit within New York's $212.7 \mathrm{~km}^{2}$ borough of Brooklyn (Conway 2011, 4), zoos can only maintain a limited number of endangered species. This number will even decrease as exhibits increase in size to meet animal welfare, while zoos are usually also very reluctant to give up popular animals that are not threatened with extinction. But even if zoos were to dedicate half their space to breeding programs for the conservation of endangered species, they would still-according to the most optimistic estimatesbe unable to accommodate more than around 800 of the 7.368 species of vertebrates that are threatened with extinction according to the 2013 IUCN Red List. ${ }^{8}$ Due to lack of space zoos are increasingly being pressed to separate grain from chaff and devote more resources to a chosen few. As Leslie Kaufman has strikingly remarked, breeding endangered animals "feels less like Noah building an ark and more like Schindler making a list" (Kaufman 2012a).

\footnotetext{
5 https://www.thedodo.com/peter-singer-on-the-animal-rig-726248280.html.

${ }^{6}$ http://www.mkhumanists.org.uk/node/73.

7 Jamieson calls his brand of utilitarianism 'progressive consequentialism' (Jamieson and Elliot 2009).

8 The list cites 1140 species of mammals, 1313 species of birds, 847 species of reptiles, 1948 species of amphibians, and 2110 species of fish.
} 
Research has shown that zoos currently hold roughly one in seven (15\%) threatened species of terrestrial vertebrates (Conde et al. 2011). ${ }^{9}$ Moreover, zoos even struggle to breed these few species because the populations are usually too small. As Sarah Long, director of the Population Management Center in Chicago, has remarked, "Noah got it all wrong. One or two or even a dozen of each species is not enough" (Kaufman 2012b). Initially, the target of zoo breeding programs was to maintain $90 \%$ of genetic variability of a species for a period of 200 years (Soulé et al. 1986). Because this time frame requires very large numbers of animals per species, it has been reduced from 200 to 100 years in the mid-1990s. But the majority of breeding programs do not have sufficient space to meet even this objective.

However, not only are the success rates of breeding programs disappointing, the prospects of reintroduction programs are also low, largely because ecological, social, economic and political aspects were not taken into consideration. Reintroduction is a costly business which often diverts attention from other, more costeffective options. In captivity, animals risk losing the skills they need to survive in the wild. Lastly, the ecosystems into which they are eventually released are dynamic systems which have often undergone dramatic changes in the time span between the breeding program and the reintroduction, sometimes as a result of anthropogenic disturbances such as $\mathrm{CO}_{2}$ emissions and deforestation. A review by Beck (1995) estimated that only 16 out of 145 reintroduction projects using captive-born animals were successful. It also showed that most animals for reintroduction do not come from zoos but from other specialized facilities. Although the situation improved after the development of the Guidelines for the Placement of Confiscated Animals (IUCN 2000), the performance of zoos regarding the reintroduction of captive-bred animals still fell far short of expectations. Instead of a guiding light, reintroduction proved to be a shooting star, "providing an eye-catching attraction but not long-term illumination for conservation" (Price and Fa 2007, 173). ${ }^{10}$

By the turn of the century, Noah's Ark seemed to have become irretrievably shipwrecked as the zoo community started to realize the limitations of ex situ (zoobased) conservation as a prelude to in situ (field-based) conservation (Lees and Wilcken 2009). The vision of the zoo as a Noah's Ark has gradually given way to a new paradigm, the 'integrated approach'. This transition becomes apparent when the first World Zoo Conservation Strategy of 1993 is compared to the new World Zoo and Aquarium Conservation Strategy of 2005. The first document explicitly describes reintroduction as the ultimate goal of ex situ conservation. The second document, on the other hand, recognizes the reintroduction of captive-bred animals

\footnotetext{
9 Invertebrates are almost absent in zoos (see "Collection Policy Options" section).

${ }^{10}$ Furthermore, many of the successful reintroductions have their own history of struggle and strife. Take, for example, the Black-footed ferret (McCarthy 2004, 196/7). In 1986, the Black-footed ferret population had diminished to a mere 18 individuals, but thanks to a captive breeding program, more than 220 now roam the prairie of the US state of Wyoming. The program was not, however, entirely plain sailing. When the kits were released they were far too blasé to make themselves scarce when predators such as eagles, coyotes and badgers arrived on the scene. The researchers tried to resolve this problem by building a mock predator. They attached wheels to a stuffed badger, which would win fame as RoboBadger. The only way the ferrets could escape RoboBadger was to find a burrow. The researchers then tried to increase the ferrets' aversion to RoboBadger by firing rubber bands at them.
} 
as a useful instrument for the conservation of wildlife, but cautions against high expectations because of the complexities of returning these animals to the wild (Price and Fa 2007, 156). It outlines a much broader conservationist role for zoos, including research, training, education, awareness campaigns and direct support for in situ projects. In the latest strategy, the primary mission of zoos is to integrate all these elements with their efforts to protect endangered species and conserve healthy ecosystems (Mace et al. 2007; Bowkett 2008; Lees and Wilcken 2009). Insofar as captive-breeding for reintroduction is considered necessary and appropriate, it should be accomplished as part of such a larger, integrated, holistic program (Hutchins 2003, 18).

This paradigm shift in the zoo's mission raises the question whether Jamieson's verdict will remain valid that the supposed benefits of the zoo, in particular its contribution to species conservation, are outweighed by the moral presumption against keeping animals. Will the integrated approach make it possible to strike a balance between animal welfare and rights on the one hand and species conservation on the other that leads to a morally more favorable evaluation of the zoo? To answer this question, I will proceed in two steps: first I will spell out the implications of the new paradigm for the zoo's core tasks; and next I will explore the collection policy options that are open to zoos in order to perform these tasks optimally.

\section{Implications of the Integrated Approach for the Zoo's Core Tasks}

In this section, I will successively discuss the impact of the integrated approach on education, awareness and advocacy; financial support and fund-raising; research and training; and population management.

\section{Education, Awareness and Advocacy}

Education in the context of the integrated approach must be fully geared to the conservation of species and wildlife. With over 700 million visitors a year, zoos have a unique opportunity to provide for such an education to large numbers of people (Gusset and Dick 2011). Research on the impact of education on zoo visitors is still in its infancy (Davey 2006; Falk et al. 2007; Marino et al. 2010), but it seems that two courses of action are absolutely essential to achieve the desired effect.

First of all, the animals should be shown in an environment which resembles their natural environment as closely as possible-where they get the best chance to develop behavior typical of their own species. This will help to prevent stereotypical behavior, which is a poor advertisement for a zoo and merely undermines the educational message. The much-desired 'naturalization' of zoos is well underway; nowadays, when zoos are designed, habitat takes precedence over taxonomic group. But the process runs up against limits. True habitats cover huge expanses of territory (look at the area covered by tigers). Moreover, it is virtually impossible to create realistic simulations of some forms of predatory behavior, such as chasing and killing prey, in captivity. Likewise, in the absence of predators, prey behavior, such as vigilance, may not be adequately exhibited in captivity (Kreger et al. 1998). 
When Seattle's Woodland Park Zoo started feeding whole sheep and goats to the big felids and whole rabbits and chickens to the small felids in the 1970s, many members of the public were aghast at the sight of flesh being torn from recognizable carcasses (Hancocks 2001, 249). They are used to it now, but feeding live animals to the cats is probably a step too far.

Secondly, the visitor must not be overcome by a numbing sense of helplessness. Awareness alone will not change behavior and it might even prove counterproductive if visitors are not afforded an opportunity to act (Sterling et al. 2007; Gwynne 2007). In his 1999 book Beyond Ecophobia, David Sobel contends that we must allow people to connect with nature and love the Earth before we ask them to save it. Most people know by now that the natural world is in trouble. When they hear that yet another ten thousand acres of rainforest were being lost while they were spending time at the zoo, they may distance themselves from, rather than connect to, the natural world which is so painful, unless they get a chance to make a difference-no matter how small.

Congo Gorilla Forest, a project of 2.7 hectares in Bronx Zoo dedicated to wild animals and habitats from central Africa, offers such a chance. It provides visitors with an opportunity to make a direct contribution to the conservation of the African rainforest by allowing them to name the project that will benefit from the threedollar supplement on their admission fee. The initiative raises one million dollars a year for fieldwork (Gwynne 2007). Another good example is the They're Calling on You campaign at Melbourne Zoo. Visitors to the gorilla enclosure are asked to donate their old mobile phones, which are then sent off for recycling. The idea is to save coltan, an ore that is mined at the expense of the gorillas' habitat, and to generate funding for their conservation. ${ }^{11}$

\section{Financial Support and Fundraising}

This is the simplest way for zoos to assist in situ conservation. Recent research has shown that zoos do indeed make a financial contribution to this cause. But investment in conservation by zoos is generally still low. It has been suggested that zoos devote at least $10 \%$ of their income to in situ conservation (Tribe and Booth 2003). Available data point to $<5 \%$ of income being spent on conservation ( $\mathrm{Fa}$ et al. 2011). This finding could reinforce the view that the mission of zoos is primarily 'window-dressing'.

Various fundraising ideas have recently been circulating. For instance, visitors could be asked to contribute 'on-the-spot' to a project of their choice (as in the case of the Congo Gorilla Forest project); 'conservation-contribution' machines could be installed so that visitors can donate cash to conserve certain species; groups of schoolchildren could be asked to adopt projects. In Australia, valued donors are taken on guided tours behind the scenes. Some feel that the time has come to set aside a percentage of the admission fee for in situ conservation projects (Conway 2003, 12).

\footnotetext{
${ }^{11}$ http://www.zoo.org.au/get-involved/act-for-wildlife/theyre-calling-on-you.
} 


\section{Research and Training}

The basic principle of research and training in the context of conservation efforts is: "Export expertise rather than repatriate animals" (Price and Fa 2007, 169). The tools and technologies developed by zoos are becoming increasingly relevant for in situ conservation as natural habitats continue to being damaged and destroyed at the current pace. Habitat loss and habitat fragmentation lead to an ongoing conversion of what were originally continuous populations to so-called 'metapopulations'. Metapopulations are collections of subpopulations, that are spread geographically over patches of habitat. Because these patches are usually small and because the movement of the animals between these patches is restricted for lack of connectivity, local extinction of subpopulations is a common event. This situation asks for metapopulation management, by which one may try to artificially perform the function of dispersal and recolonization of patches of locally endangered or extinct species.

With metapopulation management the distinction between classic in situ and ex situ conservation is gradually breaking down. As the size and genetic diversity of remaining wildlife populations is progressively declining, these populations are becoming more and more similar to ex situ populations. Accordingly, zoo-based expertise in genetic management of small populations of captive animals may be useful to the conservation of small and declining populations in the wild, whereas zoo-based skills in animal handling may be helpful in wild-to-wild translocations of animals from one site to another, to repopulate habitats where species have extirpated (Hutchins 2003; Hatchwell et al. 2007).

\section{Population Management}

Apart from research on management of small populations and wild-to-wild translocation, zoos can also contribute to metapopulation management through what has been called 'integrated species conservation planning' (IUCN 2014). The new approach to conservation is increasingly replacing captive-breeding for reintroduction that has fallen out of favor due to the growing recognition of its limits (Price and $\mathrm{Fa} \mathrm{2007,173).} \mathrm{It} \mathrm{refers} \mathrm{to} \mathrm{the} \mathrm{exchange} \mathrm{of} \mathrm{animals} \mathrm{between} \mathrm{in} \mathrm{situ} \mathrm{populations}$ (in the wild) and ex situ populations (in human care) and has also been termed a 'hybrid' (Redford et al. 2012) or 'pan situ' approach (Minteer and Collins, in preparation). On the one hand, captive populations can be used for restocking in areas with declining populations or for reintroduction in areas where populations have gone extinct; on the other hand, the demographic and genetic viability of ex situ populations can be boosted by supplying genetic founders from wildlife populations (Byers et al. 2013).

\section{Collection Policy Options}

In the previous section, I have shown how the paradigm shift in the zoo's mission will affect its core tasks. However, in order to fulfill these tasks in an optimal way 
some substantial changes have to be made with respect to the zoo's collection policy. In this section, I will discuss some of the most important options that have been proposed and that have often already been put into practice in one combination or another: creating a link between the collection and in situ conservation projects; putting more emphasis on local species and the local biogeographical region; exchanging animals among ex situ populations and between ex situ and in situ populations; and replacing big charismatic mammals with smaller species.

\section{Link Between Collection and In Situ Conservation Projects}

The species in the collection should match the zoo's conservation goals. This can be achieved by the creation of explicit connections between the animals on display and the in situ projects that are being supported, so that visitors can learn about the living conditions of the exhibited animals in the wild. This argument returns in WAZA's global strategy Building a Future for Wildlife, which also presents a good example of a link between ex situ and in situ conservation:

Pongoland in Leipzig Zoo has created a link between the ex situ conservation and breeding of chimpanzees and the attempts at in situ conservation of the Wild Chimpanzee Foundation (WCF) in Ivory Coast. The zoo is acting as guarantor for the long-term funding of projects in Tai National Park. Projects have been set up specifically to raise local awareness of the plight of chimpanzees, currently an endangered species. Visitors to Leipzig Zoo are told about the collaborations with the WCF; meantime, the local population is told about the activities at Leipzig Zoo and the research in Pongoland for the conservation of the chimpanzee (WAZA 2005, 10).

Another example is the spectacular $11.000 \mathrm{~m}^{2}$ rainforest at Zurich Zoo. This exhibition was developed in cooperation with Masoala National Park in Madagascar. Over the years, a whole string of direct and indirect links were forged between the Swiss zoo and the Madagascan park. Zurich Zoo provides the funding for small-scale development projects in communities around the park. These projects have proven highly successful in winning the support of the villagers and the local government for the park. Two nurseries have been established nearby to help the local community and to supply the zoo with seeds. Support was provided for field research in Masoala. The park was promoted in Madagascar and in Europe as a place of international importance for the conservation of biodiversity (Hatchwell and Rübel 2007).

These kinds of alliances between zoos in developed countries and protected areas in developing countries are in everyone's interests: on the one hand, they help zoos to strengthen the impact of their activities on in situ wildlife conservation; on the other, they secure long-term funding for protected areas.

Emphasis on Local Species and the Local Biogeographical Region

The link between the collection and in situ conservation projects is easier to make when more emphasis is put on local species and the local biogeographical region. A shift in breeding programs for reintroduction from exotic to indigenous species is 
entirely in keeping with Article 9 of the Convention on Biological Diversity. This article states that ex situ conservation should take place preferably in the country of origin of the biological component. Likewise, the International Union for the Conservation of Nature (IUCN) has recommended that regional zoo associations work with threatened species in their own biogeographical area (IUCN 2002; Dickie et al. 2007).

A stronger emphasis on local species and regional problems closer to home is also important from an educational perspective, given that education should preferably address problems with direct relevance for the target group. Education can encourage local involvement and action. "If the Giant panda is going to be saved, the most important audience for educational initiatives is undoubtedly in China" (Hutchins 2003, 23).

\section{Exchange of Animals Among Zoos and Between Zoos and Wildlife}

Because of limits of space, zoos can only maintain a small fraction of currently threatened species. To address this problem, zoos have a number of options. They can reduce the number of species they maintain that are not threatened and specialize in species that are. "Specialization is key to every successful threatened species propagation program" (Conway 2011, 5). In addition to specialization zoos can increase and improve regional and global cooperation. Only very few captive populations managed in isolation are self-sustaining since population sizes generally need to be very large to retain $90 \%$ of the genetic diversity over 100 years. Populations with less than 50 individuals "might have a high likelihood to be managed inadvertently or implicitly for extinction" (Fa et al. 2011, 271). The problem of low numbers can be addressed by collaborative management and the exchange of animals among zoos.

To combat the problem of numbers the interactive exchange of animals between captive and wild populations in the context metapopulation management is also a very effective strategy. The integration of in situ and ex situ programs opens the possibility to simultaneously improve the demographic stability and genetic diversity of the wild and captive populations of endangered species.

\section{A Shift Towards Smaller Species}

But the most effective strategy to combat the problem of limited space is without any doubt a shift away from the large charismatic mammals towards smaller species, particularly amphibians, invertebrates and some species of fish, which occupy less space, are relatively inexpensive to keep, have a high birth rate and are easy to reintroduce. ${ }^{12}$ Several initiatives have already been launched on this front,

\footnotetext{
12 A recent and also very promising strategy to tackle the problem of limited space concerns the creation of walkways between enclosures that allow animals greater freedom of movement. Building a network of trails, in particular top tree trails, gives animals the opportunity to rotate between various interconnected display and off-display areas. Animals may spend mornings in one area and afternoons in another. This design strategy was first applied in Philadelphia Zoo, with only 42 acres a relatively small zoo.

http://theconversation.com/zoos-of-the-future-break-down-the-enclosure-walls-26605.
} 
not least the Amphibian Conservation Action Plan, a partnership involving the World Association of Zoos and Aquariums (Gewin 2008).

The ever-present collections of charismatic megafauna-lions, tigers, giraffes, elephants, zebras, bears, hippos, and rhinos-are a poor reflection of the rich diversity of the animal kingdom. There are around 30 million animal species on this planet, 1640 of which are mammals. The average American zoo collection features 53 well-known mammals, a ratio of 1:31. The ratio for birds, at 1:98, is less than a third of this. The ratio for reptiles, at 1:104, is less still. The disproportion becomes even more alarming when it comes to very small creatures. Amphibians in the average US zoo are represented in a ratio of only 1:2000. And the ratio for invertebrates is an incredible one to several million. Over $95 \%$ of all fauna are small enough to hold in the palm of your hand, but in zoos, they are conspicuous by their absence (Hancocks 2001, 165). ${ }^{13}$

Some fear that turning the spotlight on small species will weaken the attraction of zoos. Zoos need to balance conservation credibility with commercial viability; to reach the aim of species conservation they need to attract visitors. The focus on charismatic mammals is considered to be appropriate because these animals are supposed to act as flagship species or ambassadors that raise public awareness and support for in situ conservation (Baker 2007, 147; Leader-Williams et al. 2007, 237). However, the assumption that zoos will not attract enough visitors without large mega-vertebrates is far from uncontroversial. Recent findings even suggest that small mammal displays yield a higher cost to benefit ratio, in terms of exhibit popularity per unit cost, than large mammal displays. They also suggest that imaginative displays of small-bodied species can substantially increase zoo attendance (Fa et al. 2011, 79).

A case in point is Micropia, the first museum of micro-organisms such as moulds, yeasts, (micro)algae, bacteria, archaea, and viruses. Micropia, located in Artis Royal Zoo in the center of Amsterdam, the Netherlands, opened its gates in October 2014. The museum uses 3D viewers, allowing visitors to see how living microbes move around, eat and reproduce. It has become a popular venue that has plenty of interactive displays on offer, including a body scanner which can show you what types of microbes live on your body, and a Kiss-o-meter which can count the number of microbes transferred during a kiss.

\section{Towards a New Balance Between Animal Welfare/Rights and Wildlife Conservation?}

Will the integrated approach, if rigorously applied, tip the balance between animal welfare and species conservation concerns in favor of the zoo? Most animal rights proponents will deny this possibility because they are opposed to such value balancing. However, this abolitionist position will lose normative force as the

\footnotetext{
13 Edward O. Wilson once said that it cannot be stressed enough "that, as a whole, invertebrates are more important than vertebrates for the conservation of ecosystems. If invertebrates were to die out, I fear that the human race would survive for just a few months" (Wilson 1987, 345).
} 
borderline between in situ and ex situ conservation will more and more be blurred, i.e. as zoos will increasingly become more like national parks and wildlife reserves and, vice versa, parks and reserves will take on some of the character of zoos, and hence be subject to zoo dilemmas. Like zoo populations, wild populations are increasingly becoming too small to be demographically and genetically viable and will inevitably go extinct without continuous monitoring and management. In such a situation abolitionism is tantamount to capitulation to species extinction (Minteer and Collins 2013).

On the other hand, a focus on smaller species such as reptiles, amphibians and fish might to some extent address the concerns raised by adherents of the rights view. After all, Tom Regan's rights theory does not extend to all animals, but only to those animals, notably mammals, that can be regarded as subjects-of-a-life because they have capacities for emotion, memory, belief, desire, intentional action, self-awareness, as well as conceptual abilities and a sense of the future, including their own future.

Unlike animal rights advocates, animal welfare proponents generally do allow for trade-offs between animal welfare and species conservation concerns. But most of them agree with Dale Jamieson's verdict that the zoo's contribution to species conservation is not significant enough to overcome the presumption against keeping animals in captivity. They usually also endorse Jamieson's view that we cannot save wild nature by bringing it indoors but only by setting aside large tracts of land and change our present environmentally unfriendly behavior. ${ }^{14}$ "Should zoos breed animal populations that have no home to return to?" (Hanson 2002, 171), these animal ethicists and activists ask.

But, on the other hand, one might ask if it does make any sense to preserve or create wild lands when there are only few populations left to inhabit these places. As David Hancocks has remarked, simply setting aside wild lands will not always be sufficient. He illustrates this with the example of the management plan to save the Javan tiger that was published in 1980 by the Indonesian government, assisted by the WWF and the IUCN. "It overruled any efforts at captive propagation, relying solely upon habitat protection. Today the Javan tiger is extinct" (Hancocks 2001, 175). Moreover, radically altering our present lifestyle might take too long for many endangered species to survive. All in all, an ethical position that focuses solely on the preservation of habitat will carry little normative force in a situation where in situ conservation is no longer sufficient to slow down or stop the current species extinction rate. Preserving wild lands and saving endangered species need not be exclusionary, but should be pursued together to effectively meet widespread threats such as climate change, habitat loss, poaching, invasive species and disease.

Moreover, Jamieson's unfavorable judgment of the zoo might need to be revised in light of the paradigm shift towards the integrated approach. Under this approach, the prospects for the zoo to achieve a morally acceptable balance between animal welfare costs and species conservation benefits look rather good, provided that the

\footnotetext{
14 Jamieson even blames zoos for being deeply implicated in causing the problem that they purport to be addressing; they undermine the case for preserving wild nature by taking more and more animals out of the wild (Jamieson 1995, 62).
} 
zoo's core tasks are all geared to wildlife conservation and the species collection clearly reflects the zoo's conservation goals. A shift towards small species, which generally experience less welfare problems in captivity and fewer behavioral problems that make return to the wild difficult than large animals, would certainly tip the scales in favor of the zoo. This also applies to the adoption of integrated metapopulation management. Interactive exchange of animals between captive and wild populations will greatly enhance our capacity to sustain the genetic and demographic viability of both populations. Reductions of animal welfare due to capture, research, captive breeding and reintroduction will be all the more ethically justified as the risk of extinction of small and fragmented populations in the wild will be significantly minimized.

Pie in the sky, critics of the zoo will say-and not without reason. Today, the zoo is standing at a crossroads - and has to decide if it will fully commit to the new paradigm and develop into a conservation center or if it will degenerate (further) into a venue for entertainment that will provoke increasing criticism, not only from animal protectionist but also from wildlife conservationists.

Open Access This article is distributed under the terms of the Creative Commons Attribution License which permits any use, distribution, and reproduction in any medium, provided the original author(s) and the source are credited.

\section{References}

Baker, A. (2007). Animal ambassadors: An analysis of the effectiveness and conservation impact of ex situ breeding efforts. In A. Zimmermann, M. Hatchwell, L. Dickie, \& C. West (Eds.), Zoos in the 21st century. Catalysts for conservation (pp. 139-154). Cambridge: Cambridge University Press.

Beck, B. (1995). Reintroduction, zoos, conservation, and animal welfare. In B. Norton, M. Hutchins, E. Stevens, \& T. Maple (Eds.), Ethics on the Ark (pp. 155-163). Washington: Smithsonian Institution Press.

Bowkett, A. E. (2008). Recent captive-breeding proposals and the return of the Ark concept to global species conservation. Conservation Biology, 23(3), 773-776.

Byers, O., Lees, C., Wilcken, J., \& Schwitzer, C. (2013). The one plan approach: The philosophy and implementation of CBSG's approach to integrated species conservation planning. WAZA Magazine, $14,2-5$.

Callicott, J. B. (1980). Animal liberation: A triangular affair. Environmental Ethics, 2, 311-338.

Conde, D. A., Flesness, N., Colchero, F., Jones, O. R., \& Scheuerlein, A. (2011). An emerging role of zoos to conserve biodiversity. Science, 331(6023), 1390-1391.

Conway, W. (2003). The role of zoos in the 21st century. International Zoo Yearbook, 38, 7-13.

Conway, W. (2011). Buying time for wild animals with zoos. Zoo Biology, 30, 1-8.

Davey, G. (2006). Visitor behavior in zoo: A review. Anthrozoos, 19(2), 143-157.

Dickens, M. J., Delehanty, D. J., \& Romero, L. M. (2010). Stress: An inevitable component of animal translocation. Biological Conservation, 143, 1329-1341.

Dickie, L. A., Bonner, J. P., \& West, C. (2007). In situ and ex situ conservation: Blurring the boundaries between zoos and the wild. In A. Zimmermann, M. Hatchwell, L. Dickie, \& C. West (Eds.), Zoos in the 21st century. Catalysts for conservation (pp. 220-235). Cambridge: Cambridge University Press.

Fa, J. E., Funk, S. M., \& O’Connell, D. (2011). Zoo conservation biology. Cambridge: Cambridge University Press.

Falk, J. H., et al. (2007). Why zoos \& aquariums matter: Assessing the impact of a visit to a zoo or aquarium. Silver Spring, MD: Association of Zoos \& Aquariums.

Gewin, V. (2008). Riders of a modern-day ark. PLoS Biology, 6(1), 18-21.

Gusset, M., \& Dick, G. (2011). The global reach of zoos and aquariums in visitor numbers and conservation expenditures. Zoo Biology, 30, 566-569. 
Gwynne, J. A. (2007). Inspiration for conversation: Moving audiences to care. In A. Zimmermann, M. Hatchwell, L. Dickie, \& C. West (Eds.), Zoos in the 21st century. Catalysts for conservation (pp. 52-62). Cambridge: Cambridge University Press.

Hancocks, D. (2001). A different nature. The paradoxical world of zoos and their uncertain future. Berkeley: University of California Press.

Hanson, E. (2002). Animal attractions. Nature on display in American zoos. Princeton: Princeton University Press.

Hargrove, E. C. (Ed.). (1992). The animal rights/environmental ethics debate. The environmental perspective. Albany: State University of New York Press.

Hatchwell, M., \& Rübel, A. (2007). The Masoala rainforest: A model partnership in support of in situ conservation in Madagascar. In A. Zimmermann, M. Hatchwell, L. Dickie, \& C. West (Eds.), Zoos in the 21st century. Catalysts for conservation (pp. 205-219). Cambridge: Cambridge University Press.

Hatchwell, M., Rübel, A., Dickie, L. A., West, C., \& Zimmermann, A. (2007). Conclusion: The future of zoos. In A. Zimmermann, M. Hatchwell, L. Dickie, \& C. West (Eds.), Zoos in the 21st century. Catalysts for conservation (pp. 343-360). Cambridge: Cambridge University Press.

Hutchins, M. (2003). Zoo and aquarium animal management and conservation: Current trends and future challenges. International Zoo Yearbook, 38, 14-28.

IUCN. (2000). Guidelines for the placement of confiscated animals. Gland, Switzerland.

IUCN. (2002). Technical guidelines on the management of ex situ populations for conservation. Gland, Switzerland.

IUCN. (2014). Guidelines on the use of ex situ management for species conservation. Version 2.0. Gland, Switzerland.

Jamieson, D. (1985). Against zoos. In P. Singer (Ed.), In defense of animals (pp. 108-117). New York: Basil Blackwell.

Jamieson, D. (1995). Zoos revisited. In B. Norton, M. Hutchins, E. Stevens, \& T. Maple (Eds.), Ethics on the Ark (pp. 52-66). Washington: Smithsonian Institution Press.

Jamieson, D., \& Elliot, R. (2009). Progressive consequentialism. Philosophical Perspectives, 23, 241-255.

Kaufman, L. (2012a). To save some species, zoos must let others die. New York Times, May 27.

Kaufman, L. (2012b). Zoos struggle to breed endangered animals. New York Times, July 5.

Keulartz, J., \& Swart, J. (2012). Animal flourishing and capabilities in an era of global change. In A. Thompson \& J. Bendik-Keymer (Eds.), Ethical adaptation to climate change (pp. 123-144). Cambridge, MA: The MIT Press.

Keulartz, J., \& Van der Weele, C. (2008). Framing and reframing in invasion biology. Configurations, 16(1), 93-115.

Kreger, M. D., Hutchins, M., \& Fascione, N. (1998). Context, ethics, and environmental enrichment in zoos and aquariums. In D. Shepherdson, et al. (Eds.), Second nature. Environmental enrichment for captive animals (pp. 59-82). Washington and London: Smithsonian Institution Press.

Leader-Williams, N., Balmford, A., Linkie, M., Mace, G. M., Smith, R. J., Stevenson, M., et al. (2007). Beyond the ark: conservation biologists' views of the achievements of zoos in conservation. In A. Zimmermann, M. Hatchwell, L. Dickie, \& C. West (Eds.), Zoos in the 21st century. Catalysts for conservation (pp. 236-254). Cambridge: Cambridge University Press.

Lees, C. M., \& Wilcken, J. (2009). Sustaining the Ark: The challenges faced by zoos in maintaining viable population. Zoo Yearbook, 43, 6-18.

Mace, G. M., Balmford, A., Leader-Williams, N., Manica, A., Walter, O., West, C., \& Zimmermann, A. (2007). Measuring conservation success: Assessing zoos' contribution. In A. Zimmermann, M. Hatchwell, L. Dickie, \& C. West (Eds.), Zoos in the 21st century. Catalysts for conservation (pp. 322-342). Cambridge: Cambridge University Press.

Marino, L., Lilienfeld, S. O., Malamud, R., Nobis, N., \& Brogliod, R. (2010). Do zoo and aquariums promote attitude change in visitors? A critical evaluation of the American zoo and aquarium study. Society and Animals, 18, 126-138.

McCarthy, S. (2004). Becoming a tiger. How baby animals learn to live in the wild. New York: Harper Perennial.

McShane, K. (2014). Individualist biocentrism vs. Holism revisited. Les Ateliers de l'Ethique/The Ethics Forum, 9(2), 130-148.

Minteer, B. A., \& Collins, J. P. (2013). Ecological ethics in captivity: Balancing values and responsibilities in zoo and aquarium research under rapid global change. ILAR, 54(1), 41-51. 
Minteer, B. A., \& Collins, J. P. From the wild to the walled: Ethical aspects of "Pan Situ" conservation. In B. Hale, \& A. Light (Eds.), Routledge companion to environmental ethics. London: Routledge. (in preparation).

Price, M. R. S., \& Fa, J. E. (2007). Reintroductions from zoos: A conservation guiding light or a shooting star? In A. Zimmermann, M. Hatchwell, L. Dickie, \& C. West (Eds.), Zoos in the 21st century. Catalysts for conservation (pp. 155-177). Cambridge: Cambridge University Press.

Redford, K., Jensen, D., \& Breheny, J. (2012). Integrating the captive and the wild. Science, 338, 1157-1158.

Regan, T. (1983). The case for animal rights. Berkeley: University of California Press.

Regan, T. (1995). Are zoos morally defensible. In B. Norton, M. Hutchins, E. Stevens, \& T. Maple (Eds.), Ethics on the Ark (pp. 38-51). Washington: Smithsonian Institute Press.

Rolston, H. (1988). Environmental ethics. Duties to and values in the natural world. Philadelphia: Temple University Press.

Sagoff, M. (1984). Animal liberation and environmental ethics: Bad marriage, quick divorce. Osgoode Hall Law Journal, 22, 297-307.

Sandler, R. L. (2012). The ethics of species. An introduction. Cambridge: Cambridge University Press. Schön, D., \& Rein, M. (1994). Frame reflection. New York: Basic Books.

Singer, P. (1979). Not for humans only: The place of nonhumans in environmental issues. In K. E. Goodpaster \& K. M. Sayre (Eds.), Ethics and problems of the 21st century (pp. 191-206). Notre Dame: University of Notre Dame Press.

Soulé, M. (1990). The onslaught of alien species, and other challenges in the coming decades. Conservation Biology, 4(3), 233-239.

Soulé, M., Gilpin, M., Conway, W., \& Foose, T. (1986). The millenium ark: How long a voyage, how many staterooms, how many passengers. Zoo Biology, 5, 101-113.

Sterling, E., Lee, J., \& Wood, T. (2007). Conservation education in zoos: An emphasis on behavioral change. In A. Zimmermann, M. Hatchwell, L. Dickie, \& C. West (Eds.), Zoos in the 21st century. Catalysts for conservation (pp. 37-50). Cambridge: Cambridge University Press.

Tribe, A., \& Booth, R. (2003). Assessing the role of zoos in wildlife conservation. Human Dimensions of Wildlife, 8, 65-74.

Wilson, E. O. (1987). The little things that run the world (the importance and conservation of invertebrates). Conservation Biology, 1, 344-346.

Woods, M., \& Moriarty, V. (2001). Strangers in a strange land: The problem of exotic species. Environmental Values, 10, 163-191.

World Association of Zoos and Aquariums (WAZA). (1993). Executive summary of the world zoo conservation strategy-The role of the zoos and aquaria of the world in global conservation. Gland: WAZA.

World Association of Zoos and Aquariums (WAZA). (2005). Building a future for wildlife-The world zoo and aquarium conservation strategy. Gland: WAZA. 